\title{
Treating daytime blindness with eye movement desensitization and reprocessing: a case report
}

\author{
Fatma Dilara Altunbaş
}

Department of Psychology, Üsküdar University, Institute of Social Sciences, İstanbul, Turkey

DOI: $10.18621 /$ eurj.372040

\begin{abstract}
Medically unexplained physical symptoms (MUPS) are physical complaints which are difficult to diagnose by the medical analysis. According to studies, traumatic life events, and adverse childhood experiences underlie the occurrence of MUPS. Eye movement desensitization and reprocessing (EMDR) is a therapy that is applied to treat post-traumatic stress disorder (PTSD), and recently it is known that EMDR can be used in the treatment protocol of other mental health problems. This case report demonstrates efficaciousness of EMDR therapy on PTSD-related daytime blindness (hemeralopia).
\end{abstract}

Keywords: Daytime blindness, eye movement desensitization and reprocessing, hemeralopia, medically unexplained physical symptoms, psychological trauma

Received: December 27, 2017; Accepted: April 5, 2018; Published Online: April 14, 2018

$\mathrm{M}$ edically unexplained physical symptoms (MUPS) or medically unexplained symptoms (MUS) are defined as physical complaints which are not explained by a consistent or clear organic pathology [1]. MUPS, chronic functional syndromes (CFS) or bodily distress syndrome (BDS) have been experienced by $25 \%$ to $33 \%$ of outpatients who apply to primary care services $[2,3]$. According to studies, it has been difficult to diagnose MUPS by the clinicians for many years [4], and the annual cost of it is \$256 billion dollar for the United States alone [5]. The somatic problems (such pain, ache, etc.) might affect almost all the body system.

It is known that post-traumatic stress disorder (PTSD) is associated with "ill-defined" or "medically unexplained" somatic syndromes such unexplained dizziness, tinnitus and cloudy vision, therefore syndromes that can be categorized as somatoform disorders (DSM-IV-TR); moreover a series of physical conditions, with a preponderance of cardiovascular, respiratory, musculoskeletal, neurological, and gastrointestinal disorders, chronic pain, sleep disorders and other immune-mediated disorders in lots of studies [6]. It is crucial to notice the "trauma-related MUPS" on patients who are diagnosed with PTSD. Afari et al's [7] meta-analysis displayed that people, who were exposed to a traumatic event, have 2.7 times higher risk of developing functional somatic symptoms than people who are without traumatic experiences.

Pathogenesis of trauma-related MUPS is explained with neuroscience, psychology, biology, and social processes [8]. Especially adverse childhood experiences (ACE), and lifetime traumatic events are some of the well known risk factors that lead to poor mental health outcomes [9]. According to van Rood and de Roos [10], unprocessed traumatic experiences might remain somatic complaints, triggers of the negative event, emotions and physical sensations.

Address for correspondence: Fatma Dilara Altunbaş, MA., Üsküdar University, Institute of Social Sciences, Department of Psychology, Altunizade Mh. Haluk Türksoy Sk. No:14, Üsküdar, 34662 Istanbul, Turkey

E-mail:dilarausta@gmail.com 
Cognitive behavioral therapy (CBT), graded exposure therapy, combined therapy, and EMDR are some of the implemented treatment ways for traumarelated MUPS [11]. However, some other studies report that healing effect of CBT lasts in 1 year to 5 years [12], also, most of the patients, who are diagnosed with MUPS, revert to their baseline state as a result of the discontinuation of special caring [13].

For the other therapy techniques, which are used to treat PTSD-related MUPS, it is essential to continuethe special care for a while [14]. However, the opportunity of receiving psychotherapy on a regular basis might not be provided for every patient. Also, getting successful clinical outcomes from these therapy disciplines might take a long time [15].

\section{Use of EMDR in the Treatment of Trauma-Related MUPS}

It is known that EMDR is a useful therapy technique for revealing PTSD symptoms, including trauma-related MUPS or somatoform disorders. According to van Rood and de Roos [10], unprocessed traumatic experiences might lead to unexplained physical symptoms in two ways; the first one is the complaint/pain can be experienced during the traumatic event, and this traumatic experience has not been processed properly. The second one is the stimulators in the environment might trigger the traumatic memory including the physical sensations, which were experienced during the traumatic event [10]. Symptoms of our case fit into the first definition, indeed, van der Kolk, and Fisler defined this experience as physical re-experience [16].

Some MUPS that are associated with trauma (e.g., hypochondriasis and irritable bowel syndrome) have not yet been described in case studies [10]. In this case report, a case with trauma-related MUPS and her treatment with EMDR will be presented.

\section{CASE PRESENTATION}

A 35-year-old female was kindergarten teacher and Caucasian. She applied to psychiatry clinic with complaints of a poor vision in good illumination but a better vision in poor light. She reported that she had undergone medical examinations for separate medical departments such neurology, ophthalmology, and internal diseases; according to the results, there is not found any pathology related to the problem. After the assessment session, she reported that she experienced a rape attempt from one of her family friend, who has been known by the patient for almost 5 years. According to her report, her family friend was at her family house as a guest towards evening, and she was about to leave the house to go somewhere. Later on, her family friend asked to give her a lift, and she saw no harm in accepting his request. Her family friend was driving the car and she was sitting in the front passenger seat. While the vehicle was moving, her family friend changed the direction immediately to the forest. The patient reported that the forest was extremely dark and it was almost impossible to see anything. Her family friend attempted to rape on her and she begins to grapple with him. After she put up a fight with her family friend, she could run for her life. After this event, her complaints rise to the surface and she had to resign from her kindergarten job. She could not keep children under her control in sunlight because of her limited vision.

Diagnosis of PTSD was confirmed via the Structured Clinical Interview for DSM-IV (SCID). PTSD symptom severity was assessed using the Clinician-Administered PTSD Scale (CAPS) [17, 18], whereas depression symptom severity was measured with the Beck Depression Inventory (BDI), and severity of anxiety symptoms was measured with Beck Anxiety Inventory (BAI). Measuring the effect of routine life stress, everyday traumas and acute stress were made with Impact of Events Scale-Revised (IES$\mathrm{R})$.

Following our initial assessment session and application of psychiatric scales, we tried to find a "safe place" for the patient in the second therapy session. "Safe place" is an imaginary or an existed place that must be peaceful, relax, safe, and calm for the client, moreover, a keyword is found with the client for the purpose of remembering the place. We also tested which method of Bilateral Stimulation (BLS) would work best with the patient, eye movements, and then tactile sensors were tried.

We defined a traumatic index incident with the patient, and she identified the worst picture from the traumatic memory. She identified the moment of rape attempt and grappling with her family friend as the worst picture with the associated negative belief of "I 
am insufficient", feelings of frustration, and dread, furthermore Subjective Unit of Disturbance (SUD) as 10 out of 10 , which she felt tension on her muscles. After a number of sets BLS application, she declared she had felt less distressed by the worst image but she began to feel guilty about why she entered her family friend's car. We told about her family friend was her relative and she just did what anybody would do. Then BLS was repeated for a few times, and she noticed her mind has changed and her mood became more positive. She reported that SUD as 7 out of 10, and less tension on her muscles.

At the next session, and for the most of the sessions following this, we focused the memory of how her blindness has emerged. We discussed the memory of when she first noticed her day-time blindness (on returning to her kindergarten job after a while) and after effects of her traumatic life event. Negative cognitions mostly focused on not being in control and believing she was insufficient. Whereupon the level of severity of the distress had stabilized at 2 out of 10, the positive cognition of "I did my best" was installed, that recruited for strengthening the belief of her family friend in her capability to control her distress.

At our last session, Session 9, the patient expressed that she was no longer bothered by her daytime blindness complaints. She reported that she felt less depressed and her eye vision clarity became much better than pre-treatment times. She identified the level of SUD as 0 out of 10, also she said that she believes she did her best to get rid of her family friend's rape attempt.

Table 1. Comparison of pre- and post-treatment test results

\begin{tabular}{cccc}
\hline & $\begin{array}{c}\text { Pre- } \\
\text { treatment }\end{array}$ & $\begin{array}{c}\text { Post- } \\
\text { treatment }\end{array}$ & $\begin{array}{c}\text { Follow-up } \\
\text { (3 months) }\end{array}$ \\
\hline CAPS & 75 & 10 & 7 \\
BDI & 23 & 6 & 4 \\
BAI & 14 & 3 & 3 \\
IES-R & 22 & 12 & 11 \\
\hline
\end{tabular}

$\mathrm{BAI}=$ Beck Anxiety Inventory, BDI $=$ Beck Depression Inventory, CAPS = Clinician-Administered Post-traumatic stress disorder Scale, IES-R = Impact of Events ScaleRevised
At the end of the last session, pre-treatment psychiatric and cognitive scales were applied to the patient again to compare before and after treatment scores. CAPS, BDI, BAI, and IES-R were applied during pre- and post-treatment to Miss G. Table 1 shows the before and after treatment test results.

Full written consent was obtained from the client prior to writing this article.

\section{DISCUSSION}

In our study, we found EMDR therapy is helpful to relieve symptoms of trauma-related daytime blindness and helps to eliminate the symptoms of PTSD, depression, and anxiety. In the current case report, the patient was suffering from trauma-related daytime blindness symptoms which are the poor vision in illuminated places and under sunlight, being obligated to wear sunglasses in bright field, and being incapable of doing her job as a kindergarten teacher. The outcomes of the EMDR therapy were considerable for the patient; her vision began to become much clearer under sunlight and bright field, she began to feel better about her past experiences and she has come to believe the rape attempt wasn't her fault. She became more self-confident and her depressive symptoms have been relieved.

As this case report displayed, it is clear that EMDR had a beneficial effect on the patient. In the present study, the daytime blindness (hemeralopia) was considered as trauma-related MUPS and treated with EMDR; the study is different from other MUPS and EMDR studies $[15,19,20]$ with not treating only physical pain or ache. Moreover, EMDR was not only helped to reduce the PTSD-related daytime blindness, also the treatment was beneficial to decrease anxiety and depression severity of our case.

\section{CONCLUSION}

Being exposed to traumatic life events is a risk factor to develop some medical disorders such as fibromyalgia, somatoform disorders, dissociation, anxiety disorders, and gastrointestinal problems [17]. For treatments of PTSD-related MUPS and other somatoform disorders, EMDR can be used as an 
alternative treatment option. Variety of studies applied EMDR therapy to treat medically non-diagnostic physical aches, pain or muscle tensions. The present case report is beneficial to demonstrate how adverse life events can affect human physical health beside mental health. EMDR therapy helped to prevent the continuation of harmful effects of PTSD-related hemeralopia and gaining self-confidence back.

This case report may contribute to fill the gap in the literature regarding to treat PTSD-related somatoform disorders with EMDR. More research is necessary to analyze if the method is effective with other trauma-related MUPS cases.

\section{Informed consent}

Written informed consent was obtained from the patient for the publication of this case report.

\section{Conflict of interest}

The authors declared that there are no potential conflicts of interest with respect to the research, authorship, and/or publication of this article.

\section{REFERENCES}

[1] Kirmayer L, Groleau D, Looper K, Dao M. Explaining medically unexplained symptoms. Can J Psychiatry 2004;49;663-72.

[2] Kroenke K. Patients presenting with somatic complaints: epidemiology, psychiatric comorbidity and management. Int J Methods Psychiatr Res 2003;12;34-43.

[3] Landa A, Peterson BS, Fallon BA. Somatoform pain: a developmental theory and translational research review. Psychosom Med 2012;74;717-27.

[4] Aronowitz RA. When do symptoms become a disease? Ann Intern Med 2001;134, 803-8.

[5] Barsky AJ, Orav EJ, Bates DW. Somatization increases medical utilization and costs independent of psychiatric and medical comorbidity. Arch Gen Psychiatry 2005;62,903-10.

[6] Gupta, M. Review of somatic symptoms in post-traumatic stress disorder. Int Rev Psychiatry 2013;25;86-99.

[7] Afari N, Ahumada SM, Wright LJ, Mostoufi S, Golnari G, Reis V, et al. Psychological trauma and functional somatic syndromes: a systematic review and meta-analysis. Psychosom Med 2014;76:2-11.

[8] Morton L, Elliott A, Cleland J, Deary V, Burton C. A taxonomy of explanations in a general practitioner clinic for patients with persistent "medically unexplained" physical symptoms. Patient Educ Couns 2017;100;224-30.

[9] Felitti VJ, Anda RF, Nordenberg D, Williamson DF, Spitz AM, Edwards V, et al. The relationship of childhood abuse and household dysfunction to many of the leading causes of death in adults. The Adverse Childhood Experiences (ACE) Study. Am J Prev Med 1998; $14 ; 245-58$.

[10] van Rood YR, de Roos C. EMDR in the treatment of medically unexplained symptoms: a systematic review. J EMDR Pract Res 2009;3;248-63.

[11] Donta ST, Clauw DJ, Engel CC, Guarino P, Peduzzi P, Williams DA, et al. Cognitive behavioral therapy and aerobic exercise for Gulf War veterans' illnesses: a randomized controlled trial. JAMA 2003;289;1396-404

[12] Deale, A, Husain, K, Chalder, T, Wessely, S. Long-term outcome of cognitive behavior therapy versus relaxation therapy for chronic fatigue syndrome: a 5-year follow-up study. Am J Psychiatry 2001;158;2038-42.

[13] Whiting P, Bagnall A, Sowden AJ, Cornell JE, Mulrow CD, Ramírez G. Interventions for the treatment and management of chronic fatigue syndrome. JAMA 2001;286;1360.

[14] Smith R, Lein C, Collins C, Lyles J, Given B, Dwamena F. et al. Treating patients with medically unexplained symptoms in primary care. J Gen Intern Med 2003;18;478-89.

[15] Russell MC. War-related medically unexplained symptoms, prevalence, and treatment: utilizing EMDR within the armed services. J EMDR Pract Res 2008;2;212-25.

[16] Van der Kolk BA, Fisler R. Dissociation and the fragmentary nature of traumatic memories: Overview and exploratory study. J Trauma Stress 1995;8;505-25.

[17] Aker AT, Özeren M, Başoğlu M, Kaptanoğlu C, Erol A, Buran B. [Clinician-Administered Post-Traumatic Stress Disorder Scale (CAPS): A validity and reliability study]. Türk Psikiyatri Dergisi 1999;10:28693. [Article in Turkish]

[18] Blake D, Weathers F, Nagy L, Kaloupek D, Gusman F, Charney D, et al. The development of a clinician-administered PTSD scale. J Trauma Stress 1995;8;75-90.

[19] Proudlock S. EMDR and the treatment of medically unexplained symptoms. SAGE Open 2015;5:1-5.

[20] Taycan O, Sar V, Celik C, Erdogan-Taycan S. Trauma-related psychiatric comorbidity of somatization disorder among women in eastern Turkey. Compr Psychiatry 2014;55;1837-46. 